\title{
CONSUMER BUYING BEHAVIOUR AND EFFECT OF ADVERTISEMENT MEDIAS ON TEXTILE PRODUCTS - A STUDY
}

\author{
S. MUTHUKRISHNAN \\ Research Scholar, Professor of Commerce, Dy. Dean, Kalasalingam Business School, \\ Kalasalingam University, Kalasalingam Academy of Research and Education,
}

Anand Nagar, Krishnankoil, Tamil Nadu, India

\begin{abstract}
India is a diverse country with different cultures, caste and creed. Therefore, the choice is also differ from person to person. Today, the consumption is no more a process due to the need of consumers but, in accordance with the wishes of consumers has become an evolving process. Therefore in terms of marketing, consumer behaviour in order to define their influence has become necessary to examine the factors that remain. In this study, concepts such as influences and buying behaviour are classified. The buying behaviour changes from individual to individual due to various factors socio-economic factors. There were similar studies done in other places and contexts. But similar study is not reported from Rajapalayam so far. The current study is based on a primary data collection from consumers in Rajapalayam of Virudhunagar District in Tamil Nadu. Statistical tool used is Chi-square test. The findings of the study are interesting and have practical implications.
\end{abstract}

KEYWORDS: Consumer, Buying Behavior \& Textile Products

Received: Jul 20, 2017; Accepted: Aug 08, 2017; Published: Aug 28, 2017; Paper Id.: IJBMROCT20171

\section{INTRODUCTION}

India is probably the first of all countries that perfected weaving with gold brocade and filmy muslin. The traditional textiles of India reveal the background of a rich culture that gives artistic shape and form to the ideas and ideals which inspire the lives of the people. India is a diverse country with different cultures, caste and creed. Therefore, the choice is also differ from person to person. Today, the consumption is no more a process due to the need of consumers but, in accordance with the wishes of consumers has become an evolving process.

Consumer behaviour refers to the behaviour that consumer display in searching for purchasing, using evaluating and disposing of products and services that they expect will satisfy their needs. The behaviour may be positive or negative. Positive behaviour reveals the satisfaction of a human being. Textile products mean dress materials including clothes and readymade garments meant for men, women and children- including bed sheets, pillow covers and like.

\section{REVIEW OF LITERATURE}

The literature study has been done by analyzing the various research study done by the various researcher in this regard, that is the 'consumer behaviour in textile products', hence the presence study is based on the following review.

Radha Krishna and Shylajan (2007) proposed a conceptual model and considered the influence of various 
marketing and demographic factors on consumers' habitual buying behavior towards branded articles. But identification of factors, existence of which indulges consumers to go for organized retail apparel brands are still left unturned.

According to Hasemark and Albinsson (2004) cited in Singh (2006:1) — satisfaction is an overall attitude towards a product provider or an emotional reaction to the difference between what customers expect and what they actually receive regarding the fulfillment of a needll. Kotler (2000); Hoyer \& MacInnis (2001) also define satisfaction as a person's feelings of pleasure, excitement, delight or disappointment which results from comparing a products perceived performance to his or her expectations.

The National Household Survey (2002) on market for Textile and clothing was initiated by the Textile Committee of the Government of India, in 2001, and its report was published in December 2002. The survey focused on the task of collecting and analyzing the information about the current purchase of textiles by the households in the country. It also intended to assess the effect of various factors like income, price, area, gender, fabric, etc, on the consumer demand and to ascertain the shift in demand on account of change in consumer preference. The survey reveals that the textile industry has three sectors of market, namely, the household sector, the non household sector (including industrial, medical and technical textiles), and the export sector.

Generally, every day consumers make many buying decisions. Most of the companies always do the market research to find out the existing buying behaviour of the consumer. Kotler and Amstrong ${ }^{2}$ (2001) conducted a study to find out the answers to the following queries - what consumers buy, how they buy, what and from where they buy, etc. consumer purchases are influenced strongly by cultural, social, personal and psychological characteristics. For most of the factors, the marketers cannot them, but they account it to take before marketing any decision.

Isita and Pradip (1996) did a study on factors influencing purchase of apparels from organized retail outlets. The frequent change in lifestyles with changing fashion preference of consumers is fed by the newer retail offerings coming from the organized retailers, where apparel gets utmost importance. Keeping these changing facets in view, this study makes an attempt to identify the factors of the consumers' buying behavior.

The Study focused on factors which leaves considerable impact on consumers purchase. Brand loyalty through powerful brand identity creates a major competitive advantage; a well recognized brand encourages repeat purchases (Porter \& Claycomb, 1997).

\section{SCOPE OF THE STUDY}

The study focuses on understanding the consumer buying behaviour. The study is based on the point of view of consumers. The study covers consumers residing in Rajapalayam.

\section{OBJECTIVES OF THE STUDY}

- To Study the Socio-Economic Factor Influencing the Consumer Buying Behaviour on the Textile Products.

- To Rank the effect of Advertisement Medias in buying decision on Textile products.

- To offer suggestion based on the findings.

\section{Research Design}

The study was designed to be exploratory. 


\section{Sampling Technique}

Convenience method of sampling was used for this Study.

\section{Collection of Data}

The sources of data are primary and secondary. Primary data was collected through a structured questionnaire that was distributed to the selected consumers of the Textile Products. The questionnaire consists of closed and opened ended questions and was developed by considering the various Socio - Economic factors and that influence the consumers Buying Behaviour. Secondary data has been collected from books, journals, articles and from unpublished dissertations and thesis, websites and from the companies in- house journals and records.

\section{Tools for Analysis}

Statistical tools and techniques for measuring various phenomena and analyzing the collected data effectively and efficiently to draw sound conclusion, a number of statistical techniques including percentage analysis, garret ranking technique and Chi-square test for the testing of hypothesis have been used in this study.

\section{Period of Study}

Primary data collected from the respondents during the Month of April 2017 to June 2017.

\section{Area of the Study}

The area selected for the study is Rajapalayam. It is one of the industrial towns in Tamil Nadu. It is famous for cotton textile, surgical cotton, and cement industries. The favorable climate conditions, efficient entrepreneurship, availability of capital, cheap marketing facilities and abundant supply of labour are some of the important factors responsible for the growth of textile and other industries in this town.

\section{ANALYSIS AND RESULTS}

\section{Socio-Economic Factors Influencing the Consumer Buying Behaviour on the Textile Products:}

The survey was conducted among 120 Consumers in Rajapalayam. The respondent's social classes are relatively homogeneous and enduring divisions in a society, which are hierarchically ordered and whose members share similar values, interests, and behavior's are influencing in buying. The following Socio-Economic Factors are considered: Sex, Age, Marital Status, and Size of the Family, Educational Qualification, Occupational, and Monthly Income.

In this study, consumer buying behaviour and their influence on the textile products categories as Low, High and Medium level for analytical purpose. The Level of Influence in consumers buying behavior on textile Products has been determined by the score values by adopting the Scaling Technique. The following statement has taken into consideration to ascertain the level of influence.

Table 1: Socio-Economic Factors and Their Level of Influences on the Textile Products

\begin{tabular}{|c|c|c|c|c|c|}
\hline \multirow{2}{*}{\multicolumn{2}{|c|}{ 1.Gender }} & \multicolumn{3}{|c|}{ Level of Influence } & \multirow[t]{2}{*}{ Total } \\
\hline & & Low & Medium & High & \\
\hline 1.1 & Male & $11(9.17 \%)$ & $14(11.67 \%)$ & $25(28.83 \%)$ & $50(41.67 \%)$ \\
\hline \multirow[t]{2}{*}{1.2} & Female & $15(15.50 \%)$ & $24(20.00 \%)$ & $31(25.83 \%)$ & $70(58.33 \%)$ \\
\hline & Total & $26(21.67 \%)$ & $38(31.67 \%)$ & $56(4.66 \%)$ & $120(100.00 \%)$ \\
\hline \multicolumn{6}{|c|}{ 2. Age } \\
\hline 2.1 & Up to 35 Years & $11(9.17 \%)$ & $29(24.17 \%)$ & $46(30.83 \%)$ & $86(71.67 \%)$ \\
\hline
\end{tabular}




\begin{tabular}{|c|c|c|c|c|c|}
\hline 2.2 & $35-45$ Years & $5(4.17 \%)$ & $5(4.17 \%)$ & $6(5.00 \%)$ & $16(13.33 \%)$ \\
\hline 2.3 & $45-55$ Years & $6(5.00 \%)$ & -- & $3(2.50 \%)$ & $9(7.50 \%)$ \\
\hline \multirow[t]{2}{*}{2.4} & $55-65$ Years and 65 Years & $4(3.33 \%)$ & $4(3.33 \%)$ & $1(0.82 \%)$ & $9(7.50 \%)$ \\
\hline & $\begin{array}{c}\text { Total } \\
\end{array}$ & $26(21.67 \%)$ & $38(31.67 \%)$ & $56(4.66 \%)$ & $120(100.00 \%)$ \\
\hline \multicolumn{6}{|c|}{ 3. Marital Status } \\
\hline 3.1 & Single & $7(5.83 \%)$ & $14(11.67 \%)$ & $21(17.50 \%)$ & $42(35.00 \%)$ \\
\hline 3.2 & Married & $19(15.83 \%)$ & $23(19.17 \%)$ & $35(29.17 \%)$ & $77(64.17 \%)$ \\
\hline 3.3 & Separated & -- & $1(0.83 \%)$ & -- & $1(0.83 \%)$ \\
\hline \multicolumn{2}{|c|}{ Total } & $26(21.67 \%)$ & $38(31.67 \%)$ & $56(4.66 \%)$ & $120(100.00 \%)$ \\
\hline \multicolumn{6}{|c|}{ 4. Size of the Family } \\
\hline 4.1 & Two Members & $2(1.67 \%)$ & $6(5.00 \%)$ & $11(9.17 \%)$ & $19(15.83 \%)$ \\
\hline 4.2 & $3-4$ Members & $15(12.50 \%)$ & $25(20.83 \%)$ & $35(29.17 \%)$ & $75(62.50 \%)$ \\
\hline 4.3 & $5-6$ Members & $6(5.00 \%)$ & $6(5.00 \%)$ & $8(6.67 \%)$ & $20(16.67 \%)$ \\
\hline 4.4 & Above 6 Members & $3(2.50 \%)$ & $1(0.83 \%)$ & $2(1.67 \%)$ & $6(5.00 \%)$ \\
\hline \multicolumn{2}{|c|}{$\begin{array}{c}\text { Total } \\
\end{array}$} & $26(21.67 \%)$ & $38(31.67 \%)$ & $56(4.66 \%)$ & $120(100.00 \%)$ \\
\hline \multicolumn{6}{|c|}{ 5. Educational Qualification } \\
\hline 5.1 & Up to S.S.L.C. & $11(9.17 \%)$ & $7(5.93 \%)$ & $8(6.67 \%)$ & $26(21.67 \%)$ \\
\hline 5.2 & Graduate & $3(2.50 \%)$ & $9(7.50 \%)$ & $13(10.83 \%)$ & $25(20.83 \%)$ \\
\hline 5.3 & Post-graduate & $6(5.00 \%)$ & $6(5.00 \%)$ & $11(9.17 \%)$ & $23(19.17 \%)$ \\
\hline 5.4 & Technical/ Professional & $6(5.00 \%)$ & $16(13.33 \%)$ & $24(20.00 \%)$ & $46(38.33 \%)$ \\
\hline \multicolumn{2}{|l|}{ Total } & $26(21.67 \%)$ & $38(31.67 \%)$ & $56(4.66 \%)$ & $120(100.00 \%)$ \\
\hline \multicolumn{6}{|c|}{ 6. Occupation } \\
\hline 6.1 & Agriculture/ Businessmen & $12(10.00 \%)$ & $7(5.83 \%)$ & $17(14.17 \%)$ & $36(30.00 \%)$ \\
\hline 6.2 & Professional/ Working Abroad & $8(6.67 \%)$ & $13(10.83 \%)$ & $9(7.50 \%)$ & $30(25.00)$ \\
\hline 6.3 & Govt. Employees & $2(1.67 \%)$ & $7(5.83 \%)$ & $9(7.50 \%$ & $20(16.67 \%)$ \\
\hline 6.4 & Private Employees & $4(3.33 \%)$ & $11(9.17 \%)$ & $19(15.83 \%)$ & $34(28.33 \%)$ \\
\hline \multicolumn{2}{|l|}{ Total } & $26(21.67 \%)$ & $38(31.67 \%)$ & $56(4.66 \%)$ & $120(100.00 \%)$ \\
\hline \multicolumn{6}{|c|}{ 7. Monthly Income } \\
\hline 7.1 & Up to $₹ 15,000$ & $22(18.33 \%)$ & $24(20.00 \%)$ & $30(25.00 \%)$ & $76(63.33 \%)$ \\
\hline 7.2 & $₹ 15,000-\gtrless 20,000$ & $1(0.83 \%)$ & $6(5.00 \%)$ & $10(8.33 \%)$ & $17(14.17)$ \\
\hline 7.3 & $\begin{array}{l}₹ 20,000-₹ 25,000 ₹ / 25,000-₹ \\
50,000\end{array}$ & $3(2.50 \%)$ & $7(8.83 \%)$ & $14(11.67 \%)$ & $24(20.00 \%)$ \\
\hline 7.4 & Above $₹ 50,000$ & -- & $1(0.83 \%)$ & $2(1.67 \%)$ & $3(20.50 \%)$ \\
\hline \multicolumn{2}{|l|}{ Total } & $26(21.67 \%)$ & $38(31.67 \%)$ & $56(4.66 \%)$ & $120(100.00 \%)$ \\
\hline
\end{tabular}

- From the age wise classification of the respondents, 54 (45\%) are in the age group of 25-35 years, 32 respondents $(26.67 \%)$ are in the age group of below 25 years, 16 respondents $(13.33 \%)$ are in the age group of 35-45 years.

- While considering the marital status of the respondents, it is inferred that $77(64.17 \%)$ respondents are married and the remaining $42(35 \%)$ of the respondents are unmarried.

- About 75 (62.50\%) respondents have 3-4 members in their family, 20 (16.67\%) have 5-6 members in their family, and $19(15.83 \%)$ have two members in their family.

- The data on educational qualification of the respondents reveals that $36(30 \%)$ are completed professionals, 25 $(20.84 \%)$ are graduates, and $23(19.17 \%)$ are post graduates.

- The study of the occupation reveals that 34 (28.33\%) are private employees, 24 (20\%) are professionals, and 20 $(16.67 \%)$ are government employees.

- The analysis of the Annual Income of the respondents indicates that $41(34.17 \%)$ have an income between Rs.5000 and Rs.10000, 19 (15.83\%) have an income between $₹ 10000$ and Rs.15000, and $17(14.17 \%)$ have an income between $₹ 15000$ and $₹ 20000$. 
- Out of 120 respondents, $65(54.17 \%)$ respondents have opined that medium level of influence by the residential status, $34(28.33 \%)$ respondents have opined that high level, and $13(10.83 \%)$ respondents have opined that very high level of influence.

- The study reveals that out of 120 respondents, 57 (47.50\%) respondents told that medium level of influence by the educational status, $39(32.50 \%)$ respondents told that high level influence, $10(8.33 \%)$ respondents told that very high level of influence.

- Out of 120 respondents surveyed, 66 (55\%) respondents have stated that the medium level, 30 (25\%) respondents have stated the high level, $12(10 \%)$ the respondents have stated low level of influence with the occupational status.

- About $80(66.66 \%)$ respondents mentioned medium level of influence with the economic status, 29 (24.17\%) respondents mentioned high level, and 8 (6.67\%) respondents mentioned very high level of influence with economic status.

- The study revealed that the opinion of respondents relating to the unexpected income 47 (39.17\%) respondents think that the medium level influence, 38 (31.66\%) respondents think that the low level, $20(16.67 \%)$ respondents think that the very low level influence in buying.

- The study revealed that the opinion of respondents relating to the social status 57 (47.50\%) respondents have opined that medium level influence of social status, $30(25 \%)$ respondents have opined that high level, 17 $(14.17 \%)$ respondents have opined that low level.

- Out of 120 respondents, 45 (37.50\%) respondents have mentioned medium level, $32(26.67 \%)$ respondents have mentioned low level, and $16(13.33 \%)$ respondents have mentioned very low level of influence with the political status of the respondents.

- About $52(43.33 \%)$ respondents have stated medium level of influence, 25 (20.85\%) respondents have stated low level, $20(16.67 \%)$ respondents have stated the very low level, $17(14.17 \%)$ respondents have stated high level of satisfaction about the Government policies (Globalization and Liberalization).

\section{TESTING OF HYPOTHESIS}

\section{There is No Significant Influence between the Socio-Economic Factors and their Level of Buying Behaviour on the}

\section{Textile Products}

Consumer influences are measured by the Perception Scores. The components have been used for the measurement of opinion. A perception score technique has been evolved and equal importance has been given to all consumers. For each component, there are five responses and for each response the weightage has been given in the following manner.

Table 2

\begin{tabular}{|l|c|c|c|c|c|}
\hline Weightage & $\mathbf{5}$ & $\mathbf{4}$ & $\mathbf{3}$ & $\mathbf{2}$ & $\mathbf{1}$ \\
\hline Response & Strongly Agree & Agree & No Opinion & Disagree & Strongly Disagree \\
\hline
\end{tabular}

The maximum score was 25 for each respondent and the minimum was 21 . 
The scores secured by each respondent depend upon their attitude towards the facilities in working place. With a view to finding out the influence of each component, a detailed analysis has been made.

The score values $\bar{x}+\sigma$ have been classified as high level of influence. The score values $\bar{x}-\sigma$ have been considered low level of influence. The score value in between $\bar{x}+\sigma$ and $\bar{x}-\sigma$ have been classified a medium level of influence. $\bar{x}$ and $\sigma$ being the Arithmetic Mean $(\bar{x})$ and standard Deviation $(\sigma)$ calculated from the score values of the 120 respondents. The calculated value of $\bar{x}$ and $\sigma$ are 25 and 4 respectively. Therefore,

$$
\begin{aligned}
& \bar{x}+\text { S.D. }=25+4 \text { and above }- \text { High Level of Influence } \\
& \bar{x}-\text { S.D. }=25-4 \text { and below }- \text { Low Level of Influence } \\
& (\bar{x}+\text { S.D })-(\bar{x}-\text { S.D. }) 29-21-\text { Medium Level of Influence }
\end{aligned}
$$

For testing the relationship between consumers' socio-economic background and their level of consumer satisfaction towards the facilities with working place. The respondents and their level of buying behaviour on the textile products are analyzed with help of chi-square test with the following formula.

$$
\begin{aligned}
& \chi 2=\frac{(O-E)}{E} \text { with }(\mathrm{r}-1)(\mathrm{c}-1) \text { degrees of freedom where as } \\
& \mathrm{O}=\text { Observed Frequency } \\
& \mathrm{E}=\text { Expected Frequency } \\
& \mathrm{r}=\text { Number of rows in a contingency table } \\
& \mathrm{c}=\text { Number of columns in a contingency table }
\end{aligned}
$$

\section{RESULT SHOWN AS FOLLOWS}

- $\quad \mathbf{H}_{\mathbf{0}}$ : There is no significant influence between the sex of the respondents and their level of buying behaviour on the textile products.

Since the calculated value (0.57) is less than the table value (5.99) at five per cent significant level, the null hypothesis is accepted. Hence, it could be inferred that the sex of the respondents do not influence the level on the textile products in Rajapalayam.

- $\quad \mathbf{H}_{\mathbf{0}}$ : There is no significant influence between the age of the respondents and their level of buying behaviour on the textile product.

Since the calculated value (21.73) is greater than the table value (12.6) at five per cent significant level, the null hypothesis is rejected. Hence, it could be inferred that the Age is influenced by the buying behavior of the respondents on the textile products in Rajapalayam.

- $\quad \mathbf{H}_{\mathbf{0}}$ : There is no significant influence between the marital status of the respondents and their level of buying behaviour on the textile product.

Since the calculated value (3.20) is less than the table value (9.49) at five per cent significant level, the null hypothesis is accepted. Hence, it could be inferred that the marital status does not influence the buying behaviour on the 
textile products in Rajapalayam.

- $\quad \mathbf{H}_{\mathbf{0}}$ : There is no significant influence between the size of the family of the respondents and their level of buying behaviour on the textile product.

Since the calculated value (5.49) is less than the table value (12.6) at five per cent significant level, the null hypothesis is accepted. Hence, it could be inferred that the size of the family do not influence the level of buying behavior on the textile products in Rajapalayam.

- $\mathbf{H}_{\mathbf{0}}$ : There is no significant influence between the educational qualification of the respondents and their level of buying behaviour on the textile product.

Since the calculated value (10.54) is less than the table value (12.6) at five per cent significant level, the null hypothesis is accepted. Hence, it could be inferred that the Educational Qualification do not influence buying behavior on the textile products in Rajapalayam.

- $\mathbf{H}_{\mathbf{0}}$ : There is no significant influence between the occupation of the respondents and their level of buying behaviour on the textile product.

Since, the calculated value (11.17) is less than the table value at (12.6) five per cent level of significance, the null hypothesis is accepted. Hence, it is concluded that the occupation of the respondents do not influence the level of buying behavior on the textile products in Rajapalayam.

- $\quad \mathbf{H}_{\mathbf{0}}$ : There is no significant influence between the monthly income of the respondents and their level of buying decision on effect of advertisement on the textile products.

Since, the calculated value (7.85) is less than the table value (12.6) at five per cent level of significance, the null hypothesis is accepted. Hence, it is concluded that the monthly income do not influence the buying behavior in textile products in Rajapalayam.

\section{EFFECT OF ADVERTISEMENTS ON BUYING BEHAVIOUR:}

The researcher has identified some of the factors which influenced the consumer's Buying Behaviour and their effect of advertisement media like Wall Posters, Banners, Boards, Radio, Magazine, Television, Newspapers and so on. Garret's Ranking Technique is used to study the effect of advertisement Medias'.

\section{Garret Scores}

The Garret ranks are calculated by using appropriate Garret ranking formula. Then based on the Garret ranks, the Garret Table value is ascertained. The Garret Table values and scores of each are presented in Table 3 and they are multiplied to record scores in Table 4, finally by adding each row; the total Garret scores are obtained.

Per cent position $=100(\mathrm{Rij}-0.5) / \mathrm{Nj}$.

Rij = Rank given for jth item sample respondents.

$\mathrm{Nj}=$ Total rank given by the $\mathrm{J}$ th Sample respondents. 
Table 3: Scores of Advertisement Medias in Influencing the Consumer's Buying Behaviour on Textile Products - and their Ranks

\begin{tabular}{|c|c|c|c|c|c|c|c|c|c|}
\hline \multirow[b]{2}{*}{ SI. No. } & \multirow{2}{*}{$\begin{array}{c}\text { Effect of } \\
\text { Advertisement } \\
\text { Medias } \\
\end{array}$} & \multicolumn{6}{|c|}{ RANK } & \multirow[b]{2}{*}{7} & \multirow[b]{2}{*}{ Total Score } \\
\hline & & 1 & 2 & 3 & 4 & 5 & 6 & & \\
\hline 1. & Wall Poster & 5 & 13 & 15 & 34 & 29 & 18 & 6 & 120 \\
\hline 2. & Banners & 4 & 6 & 19 & 16 & 30 & 37 & 8 & 120 \\
\hline 3. & Boards & 2 & 8 & 7 & 11 & 17 & 40 & 35 & 120 \\
\hline 4. & Radio & 17 & 14 & 12 & 21 & 11 & 7 & 38 & 120 \\
\hline 5. & Television & 74 & 24 & 9 & 3 & 4 & 1 & 5 & 120 \\
\hline 6. & Newspapers & 12 & 33 & 21 & 21 & 11 & 12 & 10 & 120 \\
\hline \multirow[t]{3}{*}{7.} & Magazine & 6 & 22 & 37 & 14 & 18 & 5 & 18 & 120 \\
\hline & Total & 120 & 120 & 120 & 120 & 120 & 120 & 120 & \\
\hline & Garret Value & 79 & 66 & 58 & 50 & 43 & 35 & 22 & \\
\hline
\end{tabular}

Table 4: Percent Position and Garret Value

\begin{tabular}{|c|c|c|c|}
\hline Sl. No. & $100 \frac{(R i j-0.5)}{N j}$ & Calculated Value & Garret Value \\
\hline 1. & $100 \frac{(1-0.5)}{7}$ & 7.14 & 79 \\
\hline 2. & $100 \frac{(2-0.5)}{7}$ & 21.42 & 66 \\
\hline 3. & $100 \frac{(3-0.5)}{7}$ & 35.71 & 58 \\
\hline 4. & $100 \frac{(4-0.5)}{7}$ & 50 & 50 \\
\hline 5. & $100 \frac{(5-0.5)}{7}$ & 64.28 & 43 \\
\hline 6. & $100 \frac{(6-0.5)}{7}$ & 78.57 & 35 \\
\hline 7. & $100 \frac{(7-0.5)}{7}$ & 92.85 & 22 \\
\hline
\end{tabular}

Source: Calculated Data

Table 5: Garret Ranking Total Scores, Average and Rank on Effect of Advertisement Medias in Influencing the Consumer to Buying Behaviour on Textile Products

\begin{tabular}{|c|l|c|c|c|}
\hline SI. No. & Advertisement Medias & Total Score & Average & Rank \\
\hline 1. & Wall Poster & 5832 & 48.60 & IV \\
\hline 2. & Banners & 5375 & 44.79 & VI \\
\hline 3. & Boards & 4543 & 37.86 & VII \\
\hline 4. & Radio & 5567 & 46.39 & V \\
\hline 5. & Television & 8419 & 70.16 & I \\
\hline 6. & Newspapers & 6507 & 54.23 & II \\
\hline 7. & Magazine & 6117 & 50.98 & III \\
\hline
\end{tabular}

Source: Computed Primary Data.

It is observed from the Table 5 that 'Television' has been ranked as the first factor for which have effect of advertisement; ' Newspaper' has been ranked second, ' Magazine 'third position, followed by ' wall Posters ' in fourth 
rank and 'Radio ' ranked as the fifth position' 'Banner ' is in sixth rank and 'Boards ' as seventh rank for that are influenced by the customers towards buying textile products.

Table 6: Effect of Advertisement Medias in Influencing the Consumer to Buy Textile Products during the Festival Seasons - Rank

\begin{tabular}{|c|c|c|c|c|c|c|c|}
\hline \multirow{2}{*}{ Festival Seasons } & \multicolumn{6}{|c|}{ RANK } & \multirow{2}{*}{ Tota } \\
\hline & 1 & 2 & 3 & 4 & 5 & 6 & \\
\hline Deepavali & 48 & 31 & 25 & 10 & 3 & 3 & 120 \\
\hline Christmas & 18 & 10 & 9 & 23 & 51 & 9 & 120 \\
\hline Ramzan & 1 & 5 & 7 & 6 & 21 & 80 & 120 \\
\hline Pongal & 17 & 39 & 28 & 19 & 12 & 5 & 120 \\
\hline New Year & 10 & 17 & 26 & 49 & 15 & 3 & 120 \\
\hline Local Festival & 26 & 18 & 25 & 13 & 18 & 20 & 120 \\
\hline Total & 120 & 120 & 120 & 120 & 120 & 120 & \\
\hline Garret Value & 7 & 64 & 55 & 46 & 37 & 23 & \\
\hline
\end{tabular}

Source: Calculated Primary Data.

Table 7: Percent Position and Garret Value

\begin{tabular}{|c|c|c|c|}
\hline Sl. No. & $100 \frac{(R i j-0.5)}{N j}$ & Calculated Value & Garret Value \\
\hline 1. & $100 \frac{(1-0.5)}{6}$ & 8.33 & 77 \\
\hline 2. & $100 \frac{(2-0.5)}{6}$ & 25 & 64 \\
\hline 3. & $100 \frac{(3-0.5)}{6}$ & 41.67 & 55 \\
\hline 4. & $100 \frac{(4-0.5)}{6}$ & 58.33 & 37 \\
\hline 5. & $100 \frac{(5-0.5)}{6}$ & 75 & 23 \\
\hline 6. & $100 \frac{(6-0.5)}{6}$ & 91.67 & 36 \\
\hline
\end{tabular}

Source: Calculated Data.

Table 8: Garret Ranking Total Scores, Average and Rank on Effect of Advertisement Medias in Influencing the Consumer to Buy Textile Products during the Festival Seasons

\begin{tabular}{|c|c|c|c|c|c|c|c|c|c|c|}
\hline \multirow{2}{*}{ S.I No } & \multirow{2}{*}{ Festival Seasons } & \multicolumn{6}{|c|}{ RANK } & \multirow{2}{*}{$\begin{array}{c}\text { Garret's } \\
\text { Score }\end{array}$} & \multirow{2}{*}{ Average } & \multirow{2}{*}{$\begin{array}{c}\text { Garret's } \\
\text { Rank }\end{array}$} \\
\hline & & 1 & 2 & 3 & 4 & 5 & 6 & & & \\
\hline 1. & Deepavali & 48 & 31 & 25 & 10 & 3 & 3 & 7695 & 64.13 & I \\
\hline 2. & Christmas & 18 & 10 & 9 & 23 & 51 & 9 & 5673 & 47.28 & $\mathbf{V}$ \\
\hline 3. & Ramzan & 1 & 5 & 7 & 6 & 21 & 80 & 3675 & 30.63 & VI \\
\hline 4. & Pongal & 17 & 39 & 28 & 19 & 12 & 5 & 6778 & 56.48 & II \\
\hline 5. & New Year & 10 & 17 & 26 & 49 & 15 & 3 & 6166 & 51.38 & IV \\
\hline 6. & Local Festival & 26 & 18 & 25 & 13 & 18 & 20 & 6253 & 52.11 & III \\
\hline
\end{tabular}

Source: Calculated Data.

It is observed from the Table 8 that 'Deepavali' has been ranked as the first factor 'Pongal' has been ranked second, 'Local Festival' third position, followed by 'New Year' in fourth rank, 'Christmas' ranked as the fifth ranked and 'Ramzan' as the sixth rank in the effect of advertisement that influenced the consumer to buy textile products. 


\section{SUGGESTION}

Manufacturers should constantly undertake marketing research to identify the most important psychological factors, which affect consumer's taste and preference of their products so as to evolve a target marketing strategy for effective exploit of the market. Marketing strategy should be employed, such as pricing strategy, brand strategy, promotional strategy, and advertising among others.

- The textile product must concentrate in pricing strategy to attract more number of users.

- More number of dealers and distributors has to be appointed.

\section{CONCLUSIONS}

The Textile Dealers in Rajapalayam have to consider various Socio - Economic factors that are influencing the buying behaviour. The effective Advertising media should be selected to reach the consumers during the festivals. Textile products must reach the consumers in all aspect to satisfy their needs and wants.

\section{REFERENCES}

1. Berry (1996). “Retailers with a Future”, Marketing Management, Vol. 5, No. 1, pp. 36-46.

2. Gupta A (2004). "Factors Affecting the Trial of Private Labels in Departmental Store: Evidence from India", The Icfai Journal of Brand Management, Vol. 1, No. 3, pp. 6-21.

3. Isita and Pradip (2010). "Factors Influencing Purchase of Apparels from Organized Retail Outlets", The IUP 76 Journal of Marketing Management, Vol. IX, Nos. 1 \& 2, pp. 73-87.

4. Jackson Donald (1999). “One More Time: How Do you Satisfy Customers”, Business Horizons, Vol. 42, pp. 71-76.

5. Johnson Kurt (1999). “Making Loyalty Programs More Rewarding”, Direct Marketing, pp. 24-26.

6. Memon (2006). "Garment Lifestyle Retailing Stores: Vis á Vis Impact of Private Labels: A Paradigm Shift”, The ICFAI Journal of Marketing Management, Vol. 5, No. 3, pp. 54-69.

7. Radha Krishna and Shylajan (2007). "Determinants of Habitual Buying Behavior: A Study on Branded Apparel”, TheIcfai Journal of Marketing Management, Vol. VI, No. 3, pp. 6-21. 